\title{
The Psychological Parameters of Athletic Injuries in Female Collegiate Athletes
}

\author{
Courtenay C. Stewart-Reiner \\ The Chicago School of Professional Psychology, USA
}

Received October 25, 2019; Revised December 30, 2019; Accepted January 13, 2020

\begin{abstract}
Copyright $\odot 2020$ by authors, all rights reserved. Authors agree that this article remains permanently open access under the terms of the Creative Commons Attribution License 4.0 International License
\end{abstract}

\begin{abstract}
Introduction/Purpose: The purpose of this study was to determine if there is a difference in the psychological parameters of life stress and anxiety as risk factors to injury. Methods: Participants in this study are female athletes [ $\mathrm{n}=51$, (36 injured, 15 non-injured) $]$ from four various sports teams (basketball, golf, soccer, and softball) at an NCAA Division I college. The participants completed four different questionnaires: an injury report, the Life Events Coping Scale for Collegiate Athletes (LESCA), the Sport Anxiety Scale (SAS), and the Sport Competition Anxiety Test (SCAT). Results: Results indicated that injured athletes experienced more life stress than non-injured athletes and this difference was statistically significant. Results also showed that in personality competitive anxiety and sport competitive anxiety, non-injured athletes have lower anxiety than injured athletes. Conclusion: This study sought to examine the differences in injured and non-injured athletes between psychological parameters that may lead to injury. The difference in life events between injured and non-injured athletes was statistically significant while the difference in personality competitive anxiety and sport competitive anxiety was not statistically significant.
\end{abstract}

Keywords Life Events, Personality Competitive Anxiety, Sport Competitive Anxiety

\section{Introduction}

There have been several different studies regarding psychological parameters and athletic injuries as well as the psychological approach when looking at the prediction and prevention of athletic injuries. Most view sport injury as damages that are done to the body sustained from participating in sports; however, this view strictly leads to the idea that an athlete is a container for components that may break down leading to the majority of research studies focusing on the medical and biomechanical aspects of these injuries (Almeida, Olmedilla, Rubio, \& Palou, 2014). The American Orthopedic Society for Sports Medicine has determined that there was no common definition of injury that has been used in the literature (Noyes, Lindenfeld, \& Marshall, 1988). Most studies have defined an injury as one that alters athletic performance and produces a time loss from participation (Noyes, Lindenfeld, \& Marshall, 1988).

Researchers have found that one of the most common reasons for terminating a relationship with sports is athletic injuries (Ivarsson et al., 2017). These injuries are associated with reactions, both emotional and cognitive, and they influence an athlete's well-being due to pain, sadness, anger, fear, or grief (Ivarsson et al., 2017). Other studies have shown that psychological factors such as ineffective coping strategies, anxiety, and stress can predict sports injuries and are an important part of athletic injury prevention (Tranaeus, Ivarsson, \& Johnson, 2015). Over recent times, a number of psychological intervention studies have been completed with the purpose of preventing sports injuries (Tranaeus, Ivarsson, \& Johnson, 2015). Tranaeus et al. (2015) competed a meta-analysis evaluating the effect of psychological athletic injury prevention interventions. The meta-analysis showed that psychological prevention programs overall have a major impact on reducing injury frequency among athletes (Tranaeus, Ivarsson, \& Johnson, 2015).

\subsection{Prediction and Prevention of Athletic Injuries}

Researchers have found an interest in psychological variables and determining whether those variables can predict injury. The main model that has been prevalent in the research of psychology of athletic injuries is the Williams and Andersen stress-based model of the prediction of injury (Williams, 2000). The Williams and Andersen model suggests that personality traits such as hardiness, competitive trait anxiety, locus of control, 
history of stressors, and coping resources are what contribute to the prediction of sports injuries (Williams, 2000). Therefore, this model then suggests that athletes with undesirable personality traits and a history of many stressors are more likely to assess a stressful and demanding athletic situation (Wadey, Evans, Hanton, \& Neil, 2012).

The first studies that focused on prediction and prevention of athletic injuries were published about three decades ago and have targeted life event stress as the predictor for sport injury occurrence (Ivarsson et al., 2017). One of the main psychological variables that has been examined is the relationship between life events and injury, even though it has been found that it may be almost impossible to directly measure the stress response mechanisms of those life events during competition (Maddison \& Prapavessis, 2005). While life stress has been one of the more frequently examined variables, anxiety is the psychological factor most commonly linked to the highest levels of worry and sporting injuries (De Pero, Minganti, Pesce, Capranica, \& Piacentini, 2013).

A study by Ford (2000) included 121 athletes who had been recruited from seven different sport teams. This study used the Life Orientation Test and The Athletic Life Experiences Survey, which requires participants to indicate, at the time of occurrence, the nature (good or bad) along with the impact of the life events that the athlete had experienced in the last 12 months (Ford, 2000). The results of this study found that those athletes with a higher self-esteem and increased optimism coped more effectively with the stress caused by life changes, regardless if they were good life changes or bad life changes (Ford, 2000). Ford's (2000) study was based off of another study conducted by Williams, which found that in 30 of 35 studies, athletic injuries occurred two to five times more in those athletes that had high life-event stress than those without high life-event stress (Andersen \& Williams, 1999). Therefore, the risk of injury could result in the increase of proportion to the level of life-event stress.

A study by Ivarsson, Johnson, and Podlog (2013) assessed whether or not stress, coping and personality would predict an injury occurrence based on a hypothesized model (Ivarsson, Johnson, \& Podlog, 2013). By completing four questionnaires, Ivarsson et al. found that negative life stress, negative life events, daily hassles, and trait anxiety were significant as predictors of injury among the 56 soccer players that participated (Ivarsson, Johnson, \& Podlog, 2013). In a previous study, Ivarsson and Johnson (2010) examined the relationship between stress, coping, and personality along with injury risk (Ivarsson \& Johnson, 2010). There were 48 participants in this study who completed five questionnaires over the course of three months and the results showed that injury could be predicted by anxiety, somatic trait anxiety, psychic trait stress, and irritability (Ivarsson \& Johnson,
2010).

Petrie et al. (2014) aimed to examine the effects of athletic identity, social support, and mental toughness on the life stress-injury relationships (Petrie, Deiters, \& Harmison, 2014). Petrie's (2014) study looked at 92 NCAA football players that were all part of one team, and, while this study did not find any significant effects between psychological factors, such as life stress, social support, and mental toughness on injury outcome, there were significant interaction effects with positive life stress in athletes who had low levels of mental toughness (Petrie, Deiters, \& Harmison, 2014). In addition, these findings suggest that athletes who have low levels of mental toughness and family social support miss more practice and competition days due to injury when they experience high levels of positive life stress. These results are consistent with the Williams and Andersen injury model, but extend it by demonstrating that mental toughness is a moderator of the relationship between positive life stress and injury outcome (Petrie, Deiters, \& Harmison, 2014). The psychological factors that influence the predictability and prevention of injury is not the only important factor when dealing with injuries. The injury itself can also be the traumatic event that causes a variety of physical and psychological stressors.

\subsection{Statement of the Problem}

While there have been several studies published that investigate similar factors, there have been very few directed solely at female collegiate athletes. The purpose of this study was to determine if there is a difference in psychological parameters of life stress and anxiety as risk factors to injury. In this study, the term injury applies to athletes who missed at least one competition game in their sport. Specifically, the research questions were:

1. Do injured athletes have more life stress than non-injured athletes?

2. Do injured athletes have more personality competitive anxiety than non-injured athletes?

3. Do injured athletes have more sport competitive anxiety than non-injured athletes?

\section{Materials and Methods}

\subsection{Setting}

The setting of this study was a small, private NCAA Division I university in the Midwestern United States with an enrollment of 4,000 to 6,000 students. The time of this study was in March during different parts of the sports teams' competitive seasons. The setting of this study for the women's basketball team was their team meeting room three weeks after their season had ended at 3:00 P.M. The setting for the women's golf team was their practice 
area located within the athletic center in the middle of their season at 3:30 P.M. The setting for the women's softball team was in the main arena of the athletic center during their pre-season at 3:00 P.M. The setting of this study for the women's soccer team was on their practice field during spring training at 11:30 A.M.

\subsection{Participants}

The respondents of this study were female athletes aged 18-22, from four different athletic teams: softball, basketball, golf, and soccer. Respondents were recruited by asking the coach for an audience with their team and then by asking the athletes to volunteer to complete the questionnaires. A total of 51 respondents, 15 non-injured and 36 injured, volunteered for the study. Out of these 51 respondents, 17 played soccer (4 non-injured, 13 injured), 8 played golf (6 non-injured, 2 injured), 9 played basketball (1 non-injured, 8 injured), and 17 played softball (4 non-injured, 13 injured). The main variables of this research are injury or no injury and the psychological parameters. The extraneous variables are life events, social support, and anxiety. With respect to pre-injury research, this research examines life events, sport competition anxiety, and social anxiety previous to injury.

\subsection{Instrumentation}

The instrumentation used for this study was an injury report, the Life Events Scale for Collegiate Athletes (LESCA), the Sport Anxiety Scale (SAS), and the Sport Competition Anxiety Scale (SCAT).

\subsubsection{Injury Report}

An injury report was developed by the researcher to indicate injuries in the last six months. The injury report also reported a pain scale of injury, initial and continuing treatment of the injury, and the number of games and practices missed.

\subsubsection{The Life Events Scale for Collegiate Athletes}

The LESCA was used to assess life-stress. The LESCA is a 69-item questionnaire used to measure positive and negative life change. Respondents were asked to report each of the events that they had experienced in the past six months. For each life event experienced, the athlete had to indicate the event's impact on an eight-point Likert-type scale (from -4 [extremely negative] to +4 [extremely positive]). By summing the respective life-events values, three life-event scores can be derived; negative, positive, and total (Maddison \& Prapavessis, 2005).

\subsubsection{The Sport Anxiety Scale}

The SAS is a 21 -item questionnaire used to measure personality-competitive anxiety. For each statement, respondents were asked to indicate how you usually feel prior or during competition on a four-point Likert-type scale (from 1 [not at all] to 4 [very much]). By summing the respective values, a score from the minimum of 21 (no anxiety) to the maximum of 84 (high anxiety) can be derived.

\subsubsection{The Sport Competition Anxiety Test}

The SCAT asks participants to respond to 15 statements reflecting how they feel when they compete in sports. Responses to ten of the statements are used to measure competitive trait anxiety, while five statements are not scored to reduce the likelihood of an internal response set bias. A high score (more than 24) indicates high competitive trait anxiety, a score of 17-24 indicates an average competitive trait anxiety and a low score (less than 17) indicates low competitive trait anxiety.

\subsection{Procedures}

Approval for this study was obtained from the University ethics committee. All female athletes were contacted to seek their willingness to participate in the study. The principal investigator contacted the team coach for a meeting. After meeting with the coaches, they contacted their players. The principal investigator met with each team of players separately. Players that volunteered were given a folder with an injury report, three questionnaires, and a pen. All volunteers completed the surveys anonymously and placed the surveys back in the folders. The principal investigator then personally collected the folders for data entry.

All research study participants were made aware of the study's purpose, their need for involvement in the study, and a timeline for their participation. All research participants received informed consent to familiarize them with the purpose of the study, the methodology, any potential risks, and the measures that were used to protect their privacy and confidentiality. The researcher respected the confidentiality and anonymity of the research participants, ensuring that the participants were participating voluntarily.

\subsection{Data Analysis}

Following the collection of all questionnaires, data analysis was performed in stages. First, each athlete's envelope was opened individually and their sport, injury, LESCA score, SAS score, and SCAT score were recorded. Second, the recorded data was split into injury and non-injury. Thirdly, all scores were entered into Microsoft Excel to calculate the mean, median, mode, range, and standard deviation for the LESCA (positive, negative, and total), SAS, and SCAT. Finally, a t-test was ran in Microsoft Excel on each set of statistics stated above to determine differences between injured and non-injured athletes. 
Table 1. Mean, Standard Error, Standard Deviation, and p-value Results

\begin{tabular}{|c|c|c|c|c|c|c|}
\hline & $\mathbf{n}$ & Life Events & Pos. Life Events & Neg. Life Events & Sport Anxiety & Sport Comp. Anxiety \\
\hline Group & & $\underline{M}$ & $\underline{M}$ & $\underline{M}$ & $\underline{M}$ & $\underline{M}$ \\
\hline & & $\underline{S E}$ & $\underline{S E}$ & $\underline{S E}$ & $\underline{S E}$ & $\underline{S E}$ \\
\hline & & $\underline{S D}$ & $\underline{S D}$ & $\underline{S D}$ & $\underline{S D}$ & $\underline{S D}$ \\
\hline Non-Injured & 15 & -5.20 & 9.73 & -16.40 & 42.30 & 3.14 \\
\hline & & 4.00 & 2.56 & 3.41 & 12.14 & 1.93 \\
\hline & & 15.48 & 9.90 & 13.21 & 38.38 & 3.92 \\
\hline Injured & 36 & -13.36 & 8.22 & -21.14 & 1.97 & 18.28 \\
\hline & & 2.25 & 1.31 & 2.42 & 11.83 & 0.79 \\
\hline p-value & & 13.50 & 7.86 & 14.53 & 0.13 & 4.76 \\
\hline
\end{tabular}

\section{Results}

\subsection{Life Events}

On average, injured athletes had a lower score (more negative life events than positive life events) on the LESCA $(M=-13.36, S E=2.25, S D=13.50)$ than those not injured $(M=-5.20, S E=4.00, S D=15.48)$. The difference, -8.16, was significant, $t(23)=1.80, p=0.04$. For the positive LESCA, on average injured athletes had a lower score (less positive life events) $(M=8.22, S E=$ $1.31, S D=7.86)$ than those not injured $(M=9.73, S E=$ $2.56, S D=9.90)$. This difference, 1.51 , was not significant, $t(22)=0.53, p=0.30$. For the negative LESCA, on average injured athletes had a lower score (more negative life events) $(M=-21.14, S E=2.42, S D=$ 14.53) than non-injured athletes $(M=-16.40, S E=3.41$, $S D=13.21)$. This difference, -4.74 was not significant $t$ $(29)=1.13, p=0.13$.

\subsection{Sport Anxiety}

On average, injured athletes had a lower score on the sport anxiety scale (less sport anxiety) $(M=38.38, S E=$ $1.97, S D=11.83)$ than non-injured athletes $(M=42.3, S E$ $=3.14, S D=12.14)$. The difference, 4.35 , was not significant, $t(26)=1.17, p=0.13$. For the sport competitive anxiety scale, injured athletes had a lower score (less competitive anxiety) $(M=18.28, S E=0.79$, $S D=4.76)$ than non-injured athletes $(M=19.93, S E=$ $1.01, S D=3.92)$. The difference, 1.65 , was not significant, $t(32)=1.29, p=0.10$.

\section{Discussion}

This study sought to examine the differences in psychological parameters that may lead to injury. While there was only a significant difference in one of the psychological predictors, the results showed that both psychological factors of life events stress and anxiety might predict the occurrence of sports injuries. First, evidence is provided that almost all athletes, non-injury or injury have a history of negative life events. With regards to the LESCA as it relates to injury, it has been found that there is a significant difference in life events between non-injury and injury, and, the difference is statistically significant. Having a history of negative life events can leave athletes finding themselves under potential stress, and, this additional stress can cause anxiety and leave an athlete open to injury as negative life events stress has been shown to be positively and strongly associated with previous research (Andersen \& Williams, 1999). This study, however, looked only at female athletes and, thus, the results may not be general to all athletes. Results also showed that female athletes with injuries had a higher amount of negative life events and a lower amount of positive life events than those without injury, which supports the previous studies of Rogers and Landers (2005) as well as Johnson and Ivarsson (2011) as well as the original research of Williams and Andersen's stress-injury model that specifies psychological factors, such as anxiety, and negative life stress can predict sports injuries. Second, evidence is provided that almost all athletes, non-injury and injury, have a high amount of sport anxiety; however, in both the SAS and the SCAT, there was no difference found between that of non-injury and injury, even due to the high anxiety scores. The lack of significant results for the two anxiety variables could be a result of a variety of factors, including the time in the current athletic season, previous injuries, coping skills, or medication.

Despite the differences that were found in this study, there are future recommendations that need to be met. This study will need to be replicated with a larger sample size as well as with different sports. Additionally, type of injury should also be noted. Because only female athletes were used, the differences may not be the same when using male athletes. It also would appear that certain psychosocial variables can interact with other 
psychosocial variables, which could also change the results of the study. The psychological variables in this study should also be compared to one another, not just to injury.

Further research on both interventions and mechanisms will provide a clearer understanding of the relationship between life event stress and injury, as well as offering programs aimed at decreasing the incidence and risk of injury (Andersen \& Williams, 1999). Larson (1996) found that much of the research in the area of the psychological aspect of athletic injuries had been conducted and reported by sport psychologist even though athletic trainers are the primary health care professional involved with athletic injuries (Larson, Starkey, \& Zaichkowsky, 1996). As studies show, few athletic trainers have any involvement with a sport psychologist. If the psychological aspect of athletic injuries is to be better understood, both sport psychologists and athletic trainers need to work cooperatively for the benefit of their primary concern: the athlete (Larson, Starkey, \& Zaichkowsky, 1996). In order to advance the knowledge, both empirical research into the psychological aspect of athletic injuries and practical application of sport psychology skills for athletic trainers need to be promoted (Larson, Starkey, \& Zaichkowsky, 1996).

\section{Acknowledgements}

I am very grateful and would like to thank all the participants in this study. I would also like to thank Dr. Kelly Helm for all of her help and support.

\section{REFERENCES}

[1] Almeida, P., Olmedilla, A., Rubio, V., \& Palou, P. (2014). Psychology in the realm of sport injury: What is it all about. Journal of Sport Psychology, 23(2), 395-400.

[2] Andersen, M., \& Williams, J. (1999). Athletic injury, psychosocial factors and perceptual changes during stress. Journal of Sports Sciences, 17, 735-741.

[3] De Pero, R., Minganti, C., Pesce, C., Capranica, L., \& Piacentini, M. (2013). The relationships between pre-competition anxiety, self-efficacy, and fear of injury in elite teamgym athletes. Kinesiology, 45(1), 63-72.

[4] Ford, I. (2000). An examination of psychosocial variables moderating the relationship between life stress and injury time-loss among athletes of a high standard. Journal of Sports Sciences, 18, 301-312.

[5] Ivarsson, A., \& Johnson, U. (2010). Psychological factors as predictors of injuries among senior soccer players. A prospective study. Journal of Sports Science and Medicine, 9, 347-352.

[6] Ivarsson, A., Johnson, U., \& Podlog, L. (2013).
Psychological predictors of injury occurrence: A prospective investigation of prrofessional Swedish soccer players. Journal of Sport Rehabilitation, 22, 19-26.

[7] Ivarsson, A., Johnson, U., Andersen, M., Tranaeus, U., Stenling, A., \& Lindwall, M. (2017). Psychosocial factors and sport injuries: Meta-analyses for prediction and prevention. Sports Medicine, 47, 353-365.

[8] Larson, G., Starkey, C., \& Zaichkowsky, L. (1996). Psychological aspects of athletic injuries as perceived by athletic trainers. The Sport Psychologist, 10, 37-47.

[9] Maddison, R., \& Prapavessis, H. (2005). A psychological approach to the prediction and prevention of athletic injury. Journal of Sport and Exercise Psychology, 27, 289-310.

[10] Noyes, F., Lindenfeld, T., \& Marshall, M. (1988). What determines an athletic injury (definition? Who determines and injury (occurrence)? The American Journal of Sports Medicine, 16(1-suppl), S-65-S-68.

[11] Petrie, T., Deiters, J., \& Harmison, R. (2014). Mental toughness, social support, and athletic identity: Moderators of the life stress-injuryy relationship in collegiate football players. Sport, Exercise, and Performance Psychology, 3(1), 13-27.

[12] Rogers, T. \& Landers, D. (2005). Mediating effects of peripheral vision in the life event stress / athletic injury relationship. Journal of Sport and Exercise Psychology, 27, 271-288.

[13] Tranaeus, U., Ivarsson, A., \& Johnson, U. (2015). Evaluation of the effects of psychological prevention interventios on sports injuries: A meta-analysis. Science and Sports, 30, 305-313.

[14] Wadey, R., Evans, L., Hanton, S., \& Neil, R. (2012). An examination of hardiness throughout the sport injury process. British Journal of Health Psychology, 17, $103-128$.

[15] Williams, J. \& Andersen, M. Psychosocial antecedents of sport injury: Review and critique of the stress and injury model. Journal of Applied Sport Psychology, 10, 5-25.

[16] Williams, J. (2000). How to identify and prevent injuries resulting from psychosocial factors. Athletic Therapy Today, 5(6), 36-37. 